\title{
MUDANÇAS NAS CARACTERÍSTICAS FÍSICO-QUÍMICAS DE UM LATOSSOLO VERMELHO-AMARELO DISTRÓFICO APÓS A IRRIGAÇÃO COM ÁGUA DE REÚSO NA CULTURA DA ALFACE-CRESPA (Lactuca sativa, L.)
}

\section{ANTONIO C. T. VARALLO ${ }^{1}$, CLAUDINEI F. SOUZA ${ }^{2}$, BRUNO DE L. SANTORO ${ }^{3}$}

RESUMO: A utilização do efluente de esgoto tratado para poupar os corpos d'água utilizados para irrigação tem sido de grande interesse na agricultura, e o uso não regulamentado desta prática pode acarretar mudanças no comportamento físico-químico do solo. Sua prática tem sido de grande interesse em vista da redução da quantidade de água retirada dos mananciais, preservando-os. Objetivou-se, neste trabalho, a avaliação dos atributos físico-químicos de um Latossolo Vermelho-Amarelo após aplicação de água de reúso. O experimento foi realizado em uma condição de casa de vegetação onde foram cultivados dois ciclos da alface-crespa (Lactuca sativa, L) com dois tratamentos, com três repetições cada: testemunhas (água de abastecimento proveniente de poço) e reúso (proveniente de esgoto local). Os resultados mostraram que não ocorreram aumentos em alguns atributos químicos de fertilidade, como ferro, magnésio, zinco, boro, potássio, nitrato, sódio e cálcio; decréscimo nos valores de matéria orgânica e manganês, além de diminuição da condutividade hidráulica e aumento na condutividade elétrica do solo. Observou-se, ainda, redução do pH no solo, além do aumento da RAS e PST. Desta forma, concluiu-se que a utilização de água de reúso para fins agronômicos deve ser de forma racional, monitorando-se, principalmente, a elevação do teor de sais no solo.

PALAVRAS-CHAVE: água de reúso, manejo, salinidade, sodicidade.

\section{PHYSICAL AND CHEMICAL CHARACTERISTICS CHANGES OF A RED-YELLOW LATOSOL AFTER IMPLEMENTATION OF WATER REUSE IN THE CULTURE OF CURLY LETTUCE (Lactuca sativa, L.)}

\begin{abstract}
The use of treated sewage effluent to save the ponds used for irrigation has been of great interest in agriculture, and the unregulated use of this practice can cause changes in physical and chemical behavior of the soil. This practice has been of great interest in view of reducing the quantity of water withdrawal from the springs and its preservation. The objective of this study is to evaluate the physical and chemical attributes of a Red-yellow Dystrophic Latosol after the implementation of water reuse. The experiment was conducted in a condition of greenhouse where were grown two rounds of curly lettuce (Lactuca sativa, L.) with two treatments with three repetitions each: witness (provisioning water) and reuse. The results did not show increases in some chemical attributes of fertility as iron, magnesium, zinc, boron, potassium, nitrate, sodium and calcium; decrease in organic matter and manganese, besides increase of hydraulic conductivity and the electrical conductivity of the soil. It was also observed a reduction of the soil $\mathrm{pH}$, besides the increase of SAR and ESP. Thus it must be concluded the application of water reuse for agricultural purposes should be in a rational way, and the elevation of salts in the soil must be monitored.
\end{abstract}

KEYWORDS: water reuse, management, salinity, sodium.

\footnotetext{
${ }^{1}$ Prof. M.Sc., Departamento de Engenharia Civil, Universidade de Taubaté - SP, antonio.varallo@yahoo.com.br.

${ }^{2}$ Prof. Dr., Departamento de Recurso Naturais e Proteção Ambiental, CCA, Universidade Federal de São Carlos, UFSCar, Araras SP, cfsouza@cca.ufscar.br.

${ }^{3}$ Eng $^{\mathrm{O}}$ Ambiental e Mestre em Agricultura e Ambiente pela UFSCar, blsantoro@ hotmail.com.

Recebido pelo Conselho Editorial em: 14-9-2009

Aprovado pelo Conselho Editorial em: 10-11-2011
} 


\section{INTRODUÇÃO}

A reutilização dos esgotos tratados, além de reduzir a quantidade de água retirada dos mananciais, preserva-os. Esta prática tem sido de grande interesse para a agricultura, levando-se em conta a grande quantidade de água normalmente necessária, em torno de $70 \%$ da disponibilidade hídrica no Brasil e cerca de $80 \%$ em alguns países (HESPANHOL, 2003). Segundo REIS et al. (2005), a reutilização da água concorre adequadamente para a sustentabilidade deste bem, e sua utilização na agricultura é uma forma alternativa de controle das fontes poluidoras nos corpos d'água, além da reciclagem dos nutrientes e aumento da produção agrícola.

Os corpos hídricos são considerados depuradores naturais de resíduos gerados pelo homem. Esta prática bastante usual compromete a qualidade do meio ambiente. O uso controlado de águas de reúso gera menor captação de recursos hídricos primários e gera, automaticamente, menos efluente lançado nos corpos d'água, conservando o recurso natural no que diz respeito a seus aspectos de qualidade e quantidade. Nesta prática, a agricultura irrigada tem gerado, através de manejos, a conservação dos corpos d'água e o aproveitamento dos nutrientes necessários às culturas agrícolas que estão presentes na água de reúso, melhorando a fertilidade do solo e aumentando a produtividade (MEDEIROS, 2005).

FREITAS et al. (2007) atentam para o problema da salinidade do solo decorrente das altas taxas de evaporação e baixa precipitação pluviométrica, e da presença em excesso de nitrato, potássio, sódio e nitrogênio total. ALVES et al. (2007), estudando os impactos da irrigação com esgoto sanitário tratado sobre solo plantando com coqueiros, e analisando os parâmetros da água ( $\mathrm{pH}$, cloreto, cálcio, magnésio, CE e RAS) e do solo ( $\mathrm{pH}$, cálcio, magnésio, CE e PST) constataram ligeiro aumento nos valores do solo, nos parâmetros analisados, porém sem atingir níveis considerados perigosos; portanto, aparentando não comprometer a cultura agrícola.

SANDRI et al. (2006) avaliaram o uso de água residuária e água de reservatório superficial no desenvolvimento da alface "Elisa" (Lactuca sativa, L.) e observaram ótimos resultados no desenvolvimento, na classificação comercial e na eficiência de água obtida com a aplicação da água residuária aplicada pelo sistema de gotejamento, em condições de ambiente protegido. VIANA et al. (2005) estudaram a tolerância desta hortaliça a diferentes níveis de salinidade de água e observaram uma tolerância moderada à salinidade na germinação e moderadamente sensível na fase de plântula e de muda.

\section{MATERIAL E MÉTODOS}

O experimento foi desenvolvido em condição de casa de vegetação, numa área do Departamento de Ciências Agrárias da Universidade de Taubaté, Estado de São Paulo, com latitude de $23^{\circ} 01^{\prime} 55,25^{\prime \prime} \mathrm{S}$ e longitude de $45^{\circ} 30^{\prime} 39,74^{\prime}$ W e elevação de $571 \mathrm{~m}$, entre os meses de maio a julho de 2008. Foram feitos seis canteiros $(1,50$ x 2,00 m), distantes lateralmente um do outro em $0,50 \mathrm{~m}$, sendo $3 \mathrm{~m}$ de um lado e $3 \mathrm{~m}$ do outro, separados por um corredor central de $0,70 \mathrm{~m}$, por onde passaram as linhas de derivação do sistema de irrigação. Três canteiros, denominados testemunhas, foram irrigados com água de abastecimento (Tst1, Tst2 e Tst3) e os três restantes com água de reúso (RsA, RsB e RsC). A água de reúso utilizada foi captada de um sistema fossa-filtro composto de um tanque séptico com $30 \mathrm{~m}^{3}$ de capacidade e função de reter a parte sólida do esgoto por até 7 dias. Após o tanque séptico, seguem dois filtros anaeróbios com $1 \mathrm{~m}^{3}$ cada, sendo o primeiro de fluxo descendente, seguido do segundo por fluxo ascendente (trabalho secundário, cuja finalidade é reter as partículas suspensas no efluente).

O esgoto provém de efluentes de banheiros, cozinha e laboratórios do prédio central do Câmpus, sendo que a parte proveniente dos laboratórios é apenas dos resíduos de lavagem das vidrarias, pois o material utilizado nos experimentos é descartado em recipientes para posterior descarte em local apropriado. Tanto da água de abastecimento quanto da de reúso foram coletadas amostras no intervalo médio dos dois ciclos da cultivar e realizadas análises dos parâmetros: CE, $\mathrm{pH}$, nitrato, sódio, cloreto, potássio, turbidez, dureza, conforme metodologia descrita pela APHA 
(1998), coliformes termotolerantes, seguindo a metodologia CETESB (2007), coliformes totais de acordo com a metodologia CETESB (2007), e RAS, de acordo com AYERS \& WESTCOT (1991). Foi realizado um sistema de irrigação por gotejamento, alimentado por um reservatório de $500 \mathrm{~L}$ para cada tipo de água. O número total de gotejadores foi de 24 por canteiro, sendo que cada gotejador foi posicionado entre duas plantas e a cada $0,15 \mathrm{~m}$ entre elas. Os gotejadores utilizados foram do tipo labirinto, da marca Plasto, modelo Tufftif, com vazão nominal de $4,1 \mathrm{~L} \mathrm{~h}^{-1}$ e pressão de $100 \mathrm{kPa}$. De cada reservatório, saiu uma linha primária percorrendo o corredor central que separa os canteiros, e destas linhas partiram as linhas secundárias para cada tipo de água, alimentando cada canteiro, dispostos de forma intercalada, em função do tipo de água.

Em cada canteiro, foram colocadas oito sondas de TDR (Time Domain Reflectometry), posicionadas quatro de cada lado, seguindo o alinhamento das segundas fileiras da cultura no sentido borda-centro, intercalando-se entre as alfaces, com espaçamento entre cada sonda de aproximadamente $0,60 \mathrm{~m}$, numa profundidade de 0-20 cm. Estas sondas foram ligadas a um Reflectômetro TDR 100 (Campbell Scientific, Logan-Utah), onde a condutividade elétrica a e umidade do solo eram monitoradas, antes da irrigação, em dias alternados. As sondas foram construídas e calibradas seguindo as metodologias propostas por MMOLAWA \& OR (2000), SOUZA et al. (2001) e SOUZA et al. (2006). Através do monitoramento da umidade do solo, foi conduzido o manejo da irrigação, e seu objetivo era o de manter a umidade na zona radicular da cultura, próximo à máxima capacidade de retenção de água no solo - capacidade de campo. Foram conduzidos dois ciclos da cultura da alface-crespa (Lactuca sativa, L.), formando-se cinco linhas de plantas, com espaçamento de $0,30 \mathrm{~m}$ entre si, no sentido longitudinal dos canteiros, e seis linhas com espaçamento de $0,35 \mathrm{~m}$ entre plantas, no sentido transversal, totalizando 30 plantas por canteiro e 180 plantas no geral. Na Figura 1, mostra-se a linha de canteiros e a cultura em diferentes estádios.

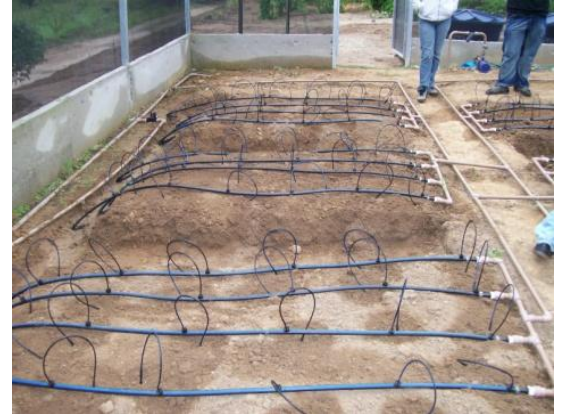

(a) montagem das linhas de irrigação

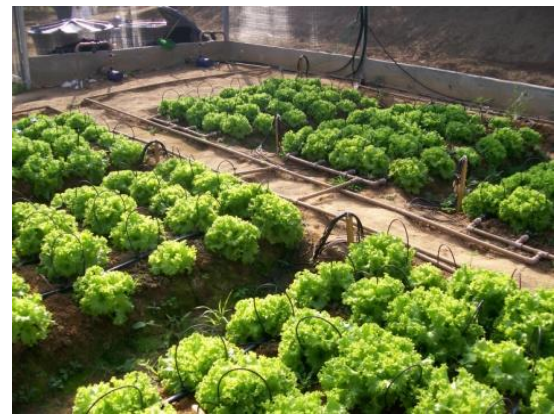

(c) cultura em pleno

desenvolvimento

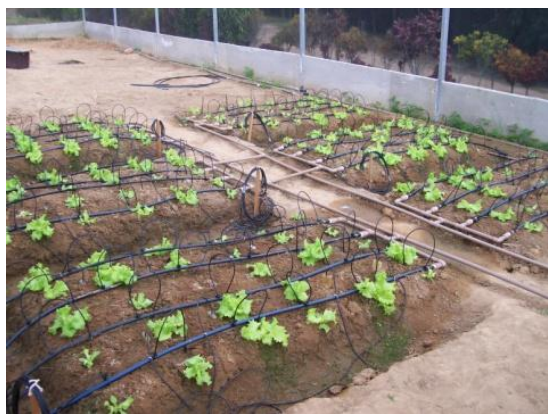

(b) cultura no estádio inicial

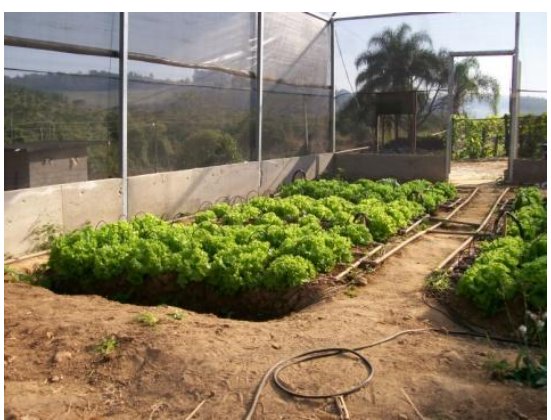

(d) cultura no estádio de colheita

FIGURA 1 (a), (b), (c) e (d). Linha de canteiros e cultura em diferentes estádios. Plot lines and crops in different stages. 
Com base na análise química de fertilidade do solo, realizado antes da montagem do experimento, foram programadas algumas correções necessárias, aplicando-se as quantidades recomendadas pelo IAC (1998). Utilizou-se fertilizante à base de nitrato de cálcio solúvel (Calcinit), fornecendo nitrogênio nítrico e cálcio solúvel em água ao mesmo tempo, na proporção de $15,5 \%$ de $\mathrm{N}$ Total e $19 \%$ de Ca para $25 \mathrm{~kg}$ do produto. Foi aplicado $1,4 \mathrm{~g}$ deste produto a cada 15 dias, durante os dois ciclos da cultura. Após o período de maturação e colheita, no final do segundo ciclo, foram coletadas amostras de solo em 6 pontos em cada parcela, nas profundidades 0-10 e 10$20 \mathrm{~cm}$. Estas amostras referentes às profundidades determinadas foram homogeneizadas e levadas para análise química do solo, onde foram determinados os seguintes parâmetros: $\mathrm{pH}, \mathrm{H}+\mathrm{Al}, \mathrm{MO}, \mathrm{P}$, $\mathrm{K}, \mathrm{Ca}, \mathrm{Mg}, \mathrm{CTC}, \mathrm{V}(\%), \mathrm{B}, \mathrm{Cu}, \mathrm{Fe}, \mathrm{Mn}$ e $\mathrm{Zn}$, conforme a metodologia descrita por RAIJ et al. (2001); além da CE, nitrato, sódio e PST, seguindo a metodologia da pasta saturada descrita por RICHARDS (1954). Também foram retiradas três amostras centrais de cada parcela, distantes entre si $0,50 \mathrm{~m}$, utilizando um trado de amostras indeformadas e cilindros de alumínio com $5,3 \mathrm{~cm}$ de altura e 4,8 cm de diâmetro para a determinação da condutividade hidráulica saturada e densidade do solo antes e após o término do experimento.

\section{RESULTADOS E DISCUSSÃO}

Ao longo do experimento, foram coletadas amostras das águas de abastecimento e de reúso utilizadas nas irrigações das parcelas testemunhas (Tst1, Tst2 e Tst3) e reúso (RsA, RsB e RsC) para a determinação dos parâmetros $\mathrm{pH}$, dureza, cloreto, turbidez, nitrato, sódio, condutividade elétrica e razão de adsorção de sódio (RAS). Os resultados médios comparativos dos parâmetros das águas de irrigação são apresentados na Tabela 1.

TABELA 1. Valores médios comparativos da qualidade da água de abastecimento e de reúso utilizadas nas irrigações. Average values of the comparative quality of supply and reused water used in irrigation.

\begin{tabular}{lcc}
\hline Parâmetros & Água de Abastecimento & Água de Reúso \\
\hline pH & 7,80 & 7,20 \\
Dureza $\left(\mathrm{mg} \mathrm{L}^{-1}\right)$ & 66,12 & 94,90 \\
Cloreto $\left(\mathrm{mg} \mathrm{L}^{-1}\right)$ & 4,60 & 77,20 \\
Turbidez & 0,90 & 15,00 \\
Nitrato $\left(\mathrm{mg} \mathrm{L}^{-1}\right)$ & 0,06 & 0,09 \\
Sódio $\left(\mathrm{mg} \mathrm{L}^{-1}\right)$ & 18,00 & 85,00 \\
Potássio $\left(\mathrm{mg} \mathrm{L}^{-1}\right)$ & 15,00 & 29,00 \\
$\left.\mathrm{CE}(\mathrm{dS} \mathrm{m})^{-1}\right)$ & 0,21 & 0,99 \\
RAS $\left(\mathrm{mmol}_{\mathrm{c}}{ }^{-1}\right)$ & 1,50 & 6,10 \\
Coliformes Totais $(\mathrm{NMP} / 100 \mathrm{~mL})$ & ------ & 90.000 \\
Termotolerantes (NMP/100 mL) & ------ & 500 \\
\hline
\end{tabular}

Pode-se observar que os parâmetros analisados na água de reúso estão acima dos encontrados na água de abastecimento. De acordo com AYERS \& WESTCOT (1991), os valores de sódio, CE e RAS possuem grau de restrição ao uso de leve a moderado; o valor de cloreto possui grau de restrição severo, e o valor de nitrato não possui nenhum grau de restrição. Estes valores encontramse dentro das diretrizes para interpretação da qualidade de água para irrigação. Foi observado um aumento da RAS aproximadamente de $306 \%$. Isto pode estar diretamente relacionado às altas concentrações de sódio e potássio presentes na água de reúso.

Quando se aplica água salina no solo, sem um manejo adequado que conduza à lixiviação destes sais, podem ocorrer problemas na permeabilidade do solo, dispersando a fração argila e diminuindo a taxa de infiltração, o que pode impedir o desenvolvimento radicular da planta. FREITAS et al. (2007) encontraram alterações químicas de dois solos (Latossolo Amarelo distrófico e Espodossolo cárbico hidromórfico) afetados pela salinidade da água, onde ocorreram 
aumentos dos teores de sódio e da RAS, além da PST do solo. De acordo com recomendações da USEPA (1992), valores de RAS inferiores a 3 não causam nenhum prejuízo; entre 3 e 9 - que seria o caso da água de reúso utilizada neste experimento, podem ocorrer prejuízos moderados. Acima destes valores, os prejuízos podem ser graves.

De acordo com AYERS \& WESTCOT (1991), águas com CE abaixo de 0,7 dS m ${ }^{-1}$ podem ser utilizadas para a irrigação sem restrição ao seu uso. Já para a água de reúso utilizada no experimento com CE de $0,99 \mathrm{dS} \mathrm{m}^{-1}$, foi realizado um monitoramente durante todo o período de execução do experimento, utilizando-se da técnica do TDR (Time Domain Reflectometry), onde foi observado variação na $\mathrm{CE}$ do solo.

Conforme mencionada na metodologia, foram coletadas amostras de solo nas parcelas (Tst1, Tst2, Tst3, RsA, RsB e RsC) para determinação de valores médios de nitrato, sódio, potássio, PST, condutividade elétrica do extrato de saturação, condutividade hidráulica e densidade do solo após o término do experimento (Tabela 2).

TABELA 2. Valores médios de nitrato, sódio, $\mathrm{CE}_{\mathrm{es}}$, Condutividade Hidráulica e PST no solo após o término do experimento nas parcelas. Average values of nitrate, sodium, $\mathbf{C E}_{\mathrm{es}}$, Hydraulic Conductivity and PST in the soil after the end of the experiment in the plots.

\begin{tabular}{lcc}
\hline Parâmetro & Parcelas Testemunhas & Parcelas com Reúso \\
\hline Nitrato $\left(\mathrm{mg} \mathrm{L}^{-1}\right)$ & 42,00 & 83,80 \\
Sódio $\left(\mathrm{mg} \mathrm{L}^{-1}\right)$ & 5,90 & 11,60 \\
Condutividade hidráulica $\left(\mathrm{mm} \mathrm{h}^{-1}\right)$ & 214,32 & 180,67 \\
PST $(\%)$ & 0,90 & 1,60 \\
Densidade do solo $\left(\mathrm{g} \mathrm{cm}^{-3}\right)$ & 1,48 & 1,46 \\
$\left.\mathrm{CE}_{\mathrm{es}}(\mathrm{dS} \mathrm{m})^{-1}\right)$ & 1,60 & 2,30 \\
\hline
\end{tabular}

Em relação a $\mathrm{CE}_{\mathrm{es}}$ do solo, verificou-se que, nas parcelas-testemunha, o solo se classificaria como não sódico e não salino, porém nas parcelas de reuso, seria classificado como sódico, segundo a classificação de solos sódicos e salinos elaborada pelo Laboratório de Salinidade dos Estados Unidos, descrita por RICHARDS (1954). Os sais adicionados ao solo através da aplicação da água de reúso podem reduzir a disponibilidade de água para a cultura, prejudicando seu desenvolvimento. Como todos os solos contêm misturas de sais solúveis que são essenciais para o desenvolvimento da cultura, o excesso, por sua vez, deve ser controlado.

Observou-se aumento da PST nas parcelas de reuso, comparando-se com as parcelas-testemunha. Este aumento poderia, com o tempo, indicar uma sodificação do solo, o que tem sido verificado com frequência na literatura científica, em experimentos com água de reúso (ALVES et al., 2007; ARAÚJO et al., 2002; BAUMGARTNER et al., 2007; DUARTE, 2006; FREITAS et al., 2007; MEDEIROS et al., 2005; MIRANDA et al., 2007; SANDRI, 2006).

Apesar de a densidade do solo não ter sofrido grandes diferenças entre as parcelas aplicadas com água de abastecimento e reúso, o aumento da PST e $\mathrm{CE}_{\mathrm{es}}$ indicam altas concentrações de sais no solo que podem ocasionar, com o tempo, dispersão das argilas, o que também poderia justificar a diminuição da condutividade hidráulica, obstruindo os poros do solo.

De acordo com PEREIRA (2006), os valores de condutividade hidráulica do solo, quando inferiores a 2,08 $\mathrm{mm} \mathrm{h}^{-1}$, são considerados baixos; valores entre 12,5 $\mathrm{mm} \mathrm{h}^{-1}$ e 41,67 $\mathrm{mm} \mathrm{h}^{-1}$ são considerados médios; e valores entre $41,67 \mathrm{~mm} \mathrm{~h}^{-1}$ e $208 \mathrm{~mm} \mathrm{~h}^{-1}$ são considerados altos. Nota-se que houve redução no valor médio da condutividade hidráulica das parcelas com reuso, comparando-as aos valores das parcelas-testemunha; porém, encontra-se dentro dos valores para solos com alta condutividade hidráulica. No presente trabalho, o uso de um filtro lento na saída da bomba de irrigação pode ter ajudado a diminuir a quantidade de material sólido suspenso na água de reúso, amenizando seus efeitos negativos no solo. 
Os valores médios dos atributos químicos do solo, encontrados após o término do segundo ciclo da cultura, estão apresentados na Tabela 3.

TABELA 3. Valores médios dos atributos químicos do solo encontrados no solo natural antes do experimento, nas parcelas testemunhas (Tst1, Tst2 e Tst3) e de reúso (RsA, RsB e RsC) após o término do segundo ciclo da cultura. Mean values of soil chemical properties found in natural soil before the experiment, inplots (Tst1, and Tst2 Tst3) and reuse (RSA, RSB and RSC) after the second crop cycle.

\begin{tabular}{|c|c|c|c|c|c|c|c|c|c|c|c|c|c|c|c|c|}
\hline & amadas & $\mathrm{pH}$ & MO & $\mathrm{P}$ & $\mathrm{K}$ & $\mathrm{Ca}$ & $\mathrm{Mg}$ & $\mathrm{H}+\mathrm{Al}$ & SB & CTC & $\mathrm{V}$ & B & $\mathrm{Cu}$ & $\mathrm{Fe}$ & $\mathrm{Mn}$ & $\mathrm{Zn}$ \\
\hline & & & $\mathrm{g} \mathrm{dm}^{-3}$ & $\begin{array}{l}\mathrm{mg} \\
\mathrm{dm}^{-3}\end{array}$ & & & & -3 & & & $\%$ & & & $\mathrm{dm}^{-3}$ & & \\
\hline Solo & & 4,7 & 16,0 & 20,0 & 3,7 & 20,0 & 7,0 & 36,0 & 30,7 & 66,7 & 46,0 & 0,2 & 1,2 & & 9,0 & 1,5 \\
\hline Méc & & 5,3 & 5,0 & 26,7 & 0,8 & 25,3 & 7,0 & 24,0 & 33,1 & 57,1 & 57,3 & 0,3 & & 59 & 3,2 & 1,6 \\
\hline $\begin{array}{l}\text { pa } \\
\text { teste }\end{array}$ & $10-20$ & 4,9 & 4,9 & 12,0 & 0,9 & 21,0 & 9,0 & 23,0 & 30,9 & 53,9 & 57,7 & 0,3 & 1,0 & 61,3 & 3,4 & 1,1 \\
\hline Média das & & 4,6 & 4,6 & 24,0 & 1,4 & 28,3 & 8,7 & 31,7 & 38,4 & 66,7 & 57,3 & 0,4 & 1,0 & 57 & 4,6 & 1,4 \\
\hline $\begin{array}{c}\text { parcelas de } \\
\text { reúso }\end{array}$ & $10-20$ & 4,6 & 4,6 & 23,0 & 1,7 & 24,0 & 9,0 & 30,3 & 34,5 & 65,0 & 53,3 & 0,9 & 1,2 & 63,0 & 5,0 & 1,4 \\
\hline
\end{tabular}

Ainda em relação ao material suspenso na água, verifica-se que a matéria orgânica presente no solo natural se encontrava com valor mais elevado em relação às parcelas após o experimento, o que sugere uma possível eficiência do sistema fossa-filtro e do filtro na saída da bomba. Sendo assim, os dados apresentados em relação ao parâmetro MO indicariam uma possível lavagem do solo durante o processo de cultivo.

Observou-se que, em relação ao $\mathrm{pH}$, ocorreu no final do experimento uma pequena acidificação nas parcelas de reúso. As águas aplicadas (abastecimento e reúso) possuíam pH de 7,8 e 7,2, respectivamente. Notou-se que, nas parcelas de abastecimento, o processo foi inverso quando comparado ao $\mathrm{pH}$ do solo natural. Salienta-se que a fertilização nitrogenada amoniacal realizada durante o experimento pode ter contribuído para esta acidificação. De acordo com SANTOS \& PEREIRA (2004), a redução do pH do solo irrigado com água de reúso pode estar relacionada à nitrificação de fontes de $\mathrm{N}$ do solo.

DUARTE (2006) relatou que a adubação nitrogenada propicia um acréscimo significativo do $\mathrm{pH}$ do solo, provavelmente pela presença de cálcio no adubo utilizado (nitrato de cálcio). A importância do $\mathrm{pH}$, muito ácido ou muito básico, pode ocasionar problemas de nutrição e toxidade na cultura.

Observando-se, ainda, os valores de fósforo, cálcio e magnésio na Tabela 3, verificou-se que não houve diferença significativa entre as parcelas-testemunha e reúso, indicando que a aplicação de água de reúso não teria afetado a quantidade existente destes elementos no solo. Porém, ressalta-se que, de acordo com SILVA \& RAIJ (1999) e DUARTE (2006), valores de fósforo acima de $120 \mathrm{mg} \mathrm{dm}^{-3}$ são considerados altos para as hortaliças, e que valores de cálcio e magnésio acima de 7 e 8 mmolc $_{c} \mathrm{dm}^{-3}$ também se encontram na faixa prejudicial à cultura.

OLIVEIRA et al. (2000) constatou, num experimento onde foi aplicado efluente de tratamento de esgoto num sistema de irrigação por subsuperfície para a cultura de pepino, aumento de $\mathrm{Ca}$ e $\mathrm{Mg}$ e diminuição de $\mathrm{P}$ no solo. Isto indicou o aproveitamento de muitos nutrientes pela cultura, pois não foi encontrada diferença nas amostras e solução de solo, apesar da presença considerável destes elementos na água de reúso utilizada por ele.

Os teores de boro (Tabela 3) nas amostras de solo encontram-se na faixa média de teor, de acordo com o IAC (1998). Apenas nas parcelas de reuso, na profundidade de 10-20 cm, foi encontrado teor de boro que enquadraria este solo como possuidor de alto teor do elemento, acima de 0,6 $\mathrm{mg} \mathrm{dm}^{-3}$. AZEVEDO \& OLIVEIRA (2005) afirmam que o teor de boro disponível no solo não sofre mudanças em função da água utilizada na irrigação; porém, como não foi realizada 
nenhuma análise da água de abastecimento ou de reúso em relação ao elemento boro e notou-se pequeno aumento em relação ao solo natural, talvez o mesmo seja proveniente das águas utilizadas.

Os teores de cobre trocável encontram-se altos (acima de $0,8 \mathrm{mg} \mathrm{dm}^{-3}$ ) de acordo com o IAC (1998). Entretanto, estes teores não se diferem, comparando-se as parcelas, o que indicaria que a água de reúso não interferiu na concentração deste elemento no solo, considerando que águas residuárias de origem doméstica geralmente possuem concentração baixa de cobre.

Não foi possível observar variação muito grande nos teores de ferro quando se comparam as parcelas-testemunha e de reúso, apesar de os valores encontrados serem muito altos, de acordo com o IAC (1998). A alta presença deste elemento no solo é característica natural do solo deste local, como pode ser observado no dado apresentado do solo natural.

A mesma explicação pode ser encontrada em relação aos teores de zinco (Tabela 3). Sua variação foi pequena em relação às parcelas estudadas, e os valores encontrados estão dentro da faixa considerada alta. A aplicação de água de reúso não causou efeito aumentativo do elemento no solo; ao contrário, houve decréscimo de $0,2 \mathrm{mg} \mathrm{dm}^{-3}$ nas médias das parcelas RsA, RsB e RsC. Isto pode ter ocorrido devido à presença de nitrogênio no solo e na água de reúso, o que favoreceu a retirada de zinco pela cultura desenvolvida.

Em relação aos teores de manganês, nota-se que os valores encontrados reportam acréscimo médio de $45 \%$ quando comparados entre as parcelas de abastecimento e reúso. Porém, quando comparados ao valor encontrado do solo natural, observa-se que, na verdade, houve um decréscimo do valor, provavelmente causado pelo processo de lixiviação do solo durante o cultivo da cultura, apesar de estes valores se encontrarem dentro do limite considerado médio, de acordo com RAIJ et al. (2001). Um dos principais fatores que afetam a solubilidade do manganês no solo é o fator pH. Solos com valores de $\mathrm{pH}$ abaixo de 5,5 podem conter muito Mn solúvel. Neste caso, recomenda-se uma atenção especial no controle do teor de $\mathrm{Mn}$, pois, devido à acidez do solo, a calagem seria indicada para o controle da mesma. DUARTE (2006) salienta que os teores de Mn e seu acúmulo no solo dependem diretamente da água de reúso usada na irrigação, além do tipo de solo, e do período de aplicação desta água.

\section{CONCLUSÕES}

O aumento do valor de alguns nutrientes e atributos do solo após a aplicação da água de reúso não alcançaram índices proibitivos da sua aplicação para uso agrícola.

A aplicação de água de reúso diminuiu a condutividade hidráulica do solo.

A RAS e PST são parâmetros que devem ser avaliados constantemente devido ao aumento de sais solúveis causados pela aplicação de água de reúso.

\section{AGRADECIMENTOS}

À Fundação de Amparo à Pesquisa do Estado de São Paulo e à Universidade de Taubaté, pelo apoio à pesquisa.

\section{REFERÊNCIAS}

ALVES, I.R.; MOTA, S.; SANTOS, A.B. dos. Avaliação das modificações nas propriedades de um solo pelo uso de esgoto doméstico tratado na irrigação do coqueiro. Revista Tecnologia, Fortaleza, v.28, n.1, p.42-50, 2007.

APHA. AMERICAN PUBLIC HEALTH ASSOCIATION. Standard methods for the examination of water and wastwater. $20^{\text {th }}$. ed. Washington, 1998. v.1-2.

ARAÚJO, G.M.; MOTA, S.; ARAÚJO, A.L.C.; OLIVEIRA, E.C.A. de. Avaliação do potencial do reúso das águas residuárias tratadas, provenientes do sistema de lagoas de estabilização de Ponta Negra em Natal - RN. In: CONGRESSO BRASILEIRO DE ENGENHARIA SANITÁRIA E 
AMBIENTAL, 23., 2002, Rio de Janeiro. Anais... Rio de Janeiro: Associação Brasileira de Engenharia Agrícola, 2002. 1 CD-ROM.

AYERS, R.S.; WESTCOT, D. W. Tradução: GHEVI, H.R.; MEDEIROS, J.F.; DAMASCENO, S.A.V. A qualidade da água na agricultura. Campina Grande: UFPB, 1991. 218 p.

AZEVEDO, L. P.; OLIVEIRA, E. L. Efeitos da aplicação de efluente de tratamento de esgoto na fertilidade do solo e na produtividade de pepino sob irrigação subsuperficial. Revista Brasileira de Engenharia Agrícola, Jaboticabal, v.25, n.1, p. 253-263, 2005.

BAUMGARTNER, D.; SAMPAIO, S.C.; SILVA, T.R.da; TEO, C.R.P.A.; VILAS BOAS, M.A. Reúso de águas residuárias da piscicultura e da suinocultura na irrigação da cultura da alface. Engenharia Agrícola, Jaboticabal, v.27, n.1, p.152-163, 2007.

COMPANHIA AMBIENTAL DO ESTADO DE SÃO PAULO. Norma Técnica L5.214.

Determinação de coliformes totais pela técnica de membrana filtrante. São Paulo, 2007.

COMPANHIA AMBIENTAL DO ESTADO DE SÃO PAULO. Norma Técnica L5.406.

Determinação de Coliformes Termotolerantes pela técnica de tubos múltiplos com meio A1. São Paulo, 2007.

DUARTE, A. de S. Reúso de água residuária tratada na irrigação da cultura do pimentão (Capsicum annum, L.). 2006. 187 f. Tese (Doutorado em Agronomia) - Escola Superior de Agricultura "Luiz de Queiroz", Universidade de São Paulo, Piracicaba, 2006.

FREITAS, E.V.S.; FERNANDES, J.G.; CAMPOS, M.C.C.; SANTOS FREIRE, M.B.G dos. Alterações nos atributos físicos e químicos de dois solos submetidos à irrigação com água salina. Revista de Biologia e Ciências da Terra, Paraíba, v.7, n.1, p.21-28, 2007.

HESPANHOL, I. Potencial de reúso de água no Brasil: agricultura, indústria, município e recarga de aquíferos. In: MANCUSO, P.C.S.; SANTOS, H.F. dos; PHILLIPPI JR, A. (Coord.). Reúso de água. Barueri, SP: Manole, 2003. p.37-95.

INSTITUTO AGRONÔMICO DE CAMPINAS. 1998. (Boletim Técnico, 100).

MEDEIROS, S. de S.; SOARES, A.A.; FERREIRA, P.A.; SOUZA, J.A.A. de; SOUZA, J.A. de; MATOS, A.T. de. Comportamento dos atributos químicos do solo em resposta à aplicação de água residuária de origem doméstica. Revista Brasileira de Engenharia Agrícola e Ambiental, Campina Grande, v.9, p.268-273, 2005. Suplemento.

MIRANDA, F.R.de; SOUZA JÚNIOR, F.E.A.; LIMA, R.N. de; CRISÓSTOMO, L.A.; SANTANA, M.G.S. de. Reúso de efluentes da carcinicultura de águas interiores na irrigação do arroz: estudo das alterações químicas no solo. In: CONGRESSO BRASILEIRO DE

ENGENHARIA AGRÍCOLA, 36., 2007, Bonito. Jaboticabal: Associação Brasileira de Engenharia Agrícola, 2007. 1 CD-ROM.

MMOLAWA, K.; OR, D. Root zone solute dynamics under drip irrigation: A review. Plant and Soil, Madison, v.222, p.163-190, 2000.

OLIVEIRA, E.L.da; PEREIRA, R.A.C.B.; LEOPOLDO, P.R. Reúso de efluente de tratamento de esgoto em irrigação por subsperfície. In: CONGRESSO BRASILEIRO DE ENGENHARIA SANITÁRIA E AMBIENTAL, 21., 2000, Rio de Janeiro. Anais... Rio de Janeiro: Associação Brasileira de Engenharia Sanitária, 2000. 1 CD-ROM.

PEREIRA, E.R. Qualidade da água residuária em sistemas de produção e de tratamento de efluentes de suínos e seu reúso na ambiente agrícola. 2006. 1.312 f. Dissertação (Doutorado em Agronomia) - Escola Superior de Agricultura "Luiz de Queiroz", Universidade de São Paulo, Piracicaba, 2006. 
RAIJ, B. van; ANDRADE, J.C. de; CANTERELLA, H.; QUAGGIO, J. A. Análise química para avaliação da fertilidade de solos tropicais. Campinas: Instituto Agronômico de Campinas, 2001. $285 \mathrm{p}$.

REIS, L.B. dos; FADIGAS, E.A.A.; CARVALHO, C.E. Energia, recursos naturais e a prática do desenvolvimento sustentável. Barueri: Manole, 2005. p.16-57.

RICHARDS, L.A. (Ed.) Diagnosis and improvement of saline and alkali soils. Washington: United States Salinity Laboratory, 1954. 160 p. (Agriculture Handbook, 60).

SANDRI, D.; MATSURA, E.E.; TESTEZLAF, R. Desenvolvimento da alface Elisa em diferentes sistemas de irrigação com água residuária. Revista Brasileira de Engenharia Agrícola e Ambiental, Campina Grande, v.11, n.1, p.17-29, 2006.

SANTOS, S.R dos; PEREIRA, G.M. Comportamento da alface tipo americana sob diferentes tensões da água no solo, em ambiente protegido. Engenharia Agrícola, Jaboticabal, v.24, n.3, p.569-577, 2004.

SILVA, F.C. da; RAIJ, B. V. Disponibilidade de fósforo em solos avaliada por diferentes extratores. Pesquisa Agropecuária Brasileira, Brasília, v.34, n.2, p.267-288, 1999.

SOUZA, C.F.; FOLEGATTI, M.V.; MATSURA, E.E.; OR, D. Calibração da Reflectometria no Domínio do Tempo (TDR) para a estimativa da concentração da solução no solo. Engenharia Agrícola, Jaboticabal, v.26, n.1, p.282-291, 2006.

SOUZA, J.T.; LEITE, V.D.; LUNA, J.G.de. Desempenho da cultura do arroz irrigado com esgotos sanitários previamente tratados. Revista Brasileira de Engenharia Agrícola e Ambiental, Campina Grande, v.5, n.1, p.107-110, 2001.

USEPA. US Environmental Protection Agency. Guidelines for Water Reuse. Washington, 1992. (EPA/625/R-92/004).

VIANA, S.M.S.; HENRIQUE, I.N.; CEBALLOS, B.S.O. de; SOUZA, J.T. de; ARAÚJO, H.W.C. de. Qualidade sanitária e produção de alface irrigada com esgoto doméstico tratado. Revista Brasileira de Engenharia Agrícola e Ambiental, Campina Grande, v.9, p.21-25, 2005. 